\title{
The Importance of Physical Environment for Guest at Restaurants in Bali
}

\author{
I Gusti Ayu Dewi Hendriyani \\ Sekolah Tinggi Pariwisata Nusa Dua Bali, Indonesia
}

\begin{abstract}
The physical environment of a restaurant today is prioritized as one of the attractions of a restaurant for its customers. Customer satisfaction is the goal of all businesses including restaurants. Customer satisfaction is a dynamic condition associated with fulfilling customer expectations of the service experience that has been provided. In the field of tourism especially providers of products and services such as restaurants, satisfied customers can cause customers to come back to the restaurant. The purpose of this study is to determine the factors and variables that can satisfy customers at restaurants in Bali. The study sites are located on 10 locations at 22 new restaurants in Bali. The method of this research is quantitative method with confirmatory factor analysis with 105 respondents. The observed factors consist of six factors that are: (1) facility aesthetics factor; (2) ambience factor; (3) lighting factor; (4) layout factor; (5) table setting factors; and (6) service staff factor. The results of this research show that the role of the physical environment in customer satisfaction at restaurants in Bali as a whole is in good condition. The most determining factor of customer satisfaction is the atmosphere factor followed by the facility aesthetics factor. The variable that most determines customer satisfaction is comfortable room temperature followed by clean furniture. Strategic implementation for the restaurant based on the results of this study is that the manager can improve factors and variables that have been good and improve factors and variables that have not been good.
\end{abstract}

Keywords: physical environment, guest satisfaction, restaurant

\section{Introduction}

There are many factors that affect whether a restaurant will be profitable in its business or not. These factors include the menu offered, the cost of food, other variable costs, marketing efforts, the management, human resource, and more. On the other hand, there are things that are often overlooked such as factors that contribute to long-term profitability of the atmosphere of the restaurant itself. Research has shown that the atmosphere can affect everything from customer perceptions to a restaurant related to the value of reliability and responsiveness. Customers can decide to go back to a restaurant not depending on how much and how fast customers eat, how much they spend on food, and how long they stay in the restaurant. Restaurant owners can set the restaurant's atmosphere appropriately, so that customers will feel comfortable and enjoy themselves in the restaurant. When the customer is satisfied, he/she will become a loyal customer as a regular customer which of course will provide benefits for the restaurant (Tuzunkan \& Albayrak, 2016).

I Gusti Ayu Dewi Hendriyani, Lecturer on Hospitality Management, Sekolah Tinggi Pariwisata Nusa Dua Bali. Email: dewi.hendriyani2@gmail.com. 
In Bali, there are many new restaurants that provide food and beverage services for their customers. Restaurant customers in Bali are not only foreign and domestic tourists but also local Balinese themselves who want to try to eat outdoors on a regular basis every month. Intense business competition requires the owners and managers of restaurants to have a great strategy in order to survive in business competition in the long term and can provide services for all visitors. According to information from TripAdvisor 2017, from some food blogger, social media, and field survey, there are 22 new restaurants in Bali which are often visited and recommended to visit. Names of those restaurants are: Sisterfield, La Plancha, The Junction Seminyak, Single Fin, Cafe Bali, Betelnut Cafe, Grocer \& Grind, Orchid Tea, Creamy Comfort, Shearlock, Angelita Patisserie, LeSica Bali, Expresso Revolver, Bistro Gardens, Livingstone Bakery, Sea Circus, La Laguna, Nook Bali, La Favela, Pomegranate Cafe, The Bistrot, and Mexicola.

The influence of the restaurant's physical environment on customer behavior has long been studied by scientists in various countries. Various studies have tested the influence of physical environmental factors on price perceptions and then the influence of the perception of prices on the intention of repurchase. The physical environment of a restaurant is the first element that customers will experience after entering a restaurant, forming a key factor for customers. In fact, customers want to eat at a restaurant not only for their nutritional needs but also to form a memorable experience, to get along with others, and to get away from the problems and routines of life. For this reason, the restaurant's physical environment needs to provide elements of interest to customers. The physical environment is an important determinant of consumer psychology and behavior in a restaurant. Satisfied customers will tell their colleagues about their experience so that this can be part of a word of mouth business in the name of the restaurant. Word of mouth promotion has proven to be one of the most effective and trusted forms in a company's marketing efforts. Although difficult to measure, oral recommendations from colleagues undoubtedly have a positive long-term impact on the profitability of a restaurant. So a restaurant is expected to provide the best atmosphere and experience for its customers.

The purpose of this research is to know the factors that most influence the customer satisfaction to physical environment at restaurants in Bali, to know the variables that most influence the customer satisfaction to physical environment at restaurants in Bali, and to know the overall assessment of customer to physical environment of restaurants in Bali. The benefits of the research results are theoretically that in order to know the assessment of customer to physical environment at restaurants in Bali and practically for local government of Bali, as input in developing Bali as a world destination, for tourism industry, as input in making decisions for arrangement of physical environment of restaurants in order to compete with its competitors.

\section{Literature Review}

According to the research by Ryu and Han (2011), there is a conceptual model to examine it: "How customer satisfaction and loyalty are influenced by their perceptions of the physical environment”? Their research uses structural equation model analysis and indicates that facility aesthetics, lighting, layout, and service staff have a significant influence on customer satisfaction. Research by Ryu and Jang (2008) developed the DINESCAPE scale to examine the dimensions of the formal restaurant's physical environment. Their study reviews relevant literature, especially environmental and marketing psychology empirically and theoretically. They also refined the scale of some items to assess DINESCAPE in a formal restaurant. Based on quantitative analysis, the six-factor scale identified in this research consists of: facility aesthetics, atmosphere, lighting, product service, layout, and social factor. Research by Wall and Berry (2007) examined dining experiences on 
formal restaurants and presented at least three important factors. Although the quality of food is very basic, the atmosphere and performance of the service greatly affect the customer ratings for a restaurant. There are several key factors in the assessment of eating experience in a restaurant: functional factors (elements of atmosphere, design, and technical) and human factors (elements of performance, behavior, and appearance of employees). Customer perception of function factor has a bigger effect than human factor, although both should always be considered for restaurant managers to maintain the quality of service provided to its customers. Research by Elina (2016) examines physical environment using questionnaires as a means of data collection. The results showed that facility aesthetics and table settings have a positive and significant impact on consumer's buying interest, while ambience, lighting, layout, and service staff have a positive but not significant effect. The results show that facility aesthetics as the most dominant factor affects customer's buying interest. All the above research can be the basis of consideration in this research on the role of the physical environment in customer satisfaction at restaurants in Bali.

Physical environment can also be called an atmosphere, which can be more influential than the product itself in determining the purchase. In some cases, the physical environment becomes a major influence for consumers (Ryu, 2005). Ryu (2005) stated that the atmosphere is an attempt to design a purchasing environment to create specific emotions that can increase the likelihood of consumers making purchases. In capturing how consumers perceive the physical environment in restaurants, Ryu and Jang (2007) used DINESCAPE. DINESCAPE focuses on the inside of restaurants and does not cover the external environment such as parking spaces and building designs, and does not include inside non-dining areas such as toilets and customer's waiting areas. Ryu and Han (2011) categorized DINESCAPE into several elements: (1) facility aesthetics, meaning all architectural design, interior design, and decoration that contribute to the attractiveness of the restaurant's neighborhood. It is important for customers to get the overall color, decor, and overall ambience to create a valuable experience for customers. Facility aesthetics includes various furniture, drawings or paintings, plants or flowers, ceiling decorations, and wall decorations which can be an important part of marketing tools by influencing customer responses such as attitudes, emotions, perceptions of prices, perceptions of value, consumer satisfaction and behavior (Ryu \& Jang, 2007); (2) ambience, which is an intangible element as a backdrop that aims to influence the senses in a non-visual way that unconsciously affects the customer. Ambience encompasses the music, aroma, and temperature inside the restaurant. Kim and Moon (2009) revealed that ambience has the strongest relationship in consumer perception and has a stronger relationship with the feeling of customer satisfaction; (3) lighting plays a role in customer convenience. Different types of lighting can affect individual customer's perceptions of space and alter customer sensitivity from the physical, psychological, and emotional aspects of an area and affect customer's buying behavior. According to Hussain and Ali (2015), lighting aims at giving a positive effect to products sold by business people. Lighting creates a sense of fun and has a positive impact on customer's purchasing behavior; (4) layout, which is one of the elements that give pleasure in a middle-up restaurant. Layout refers to the placement of objects such as machines, equipment, and furnishings arranged in an environment. Lin (2004) said that the location of a dining table within a restaurant has a profound effect on the overall consumer experience. The placement of the table has the function of providing privacy, describing the desired facilities, and acting as the distance between one customer and another. A good layout will create a positive impression for customers so customers will stay longer and make more purchases (Banat \& Wandebori, 2012); (5) table setting, which becomes one of the important physical environment elements in the middle to upper class restaurant. How to 
design a table by putting flowers or candles as a decoration can also be useful to make customers feel that they are in a good environment. Table settings can influence cognitive responses (disconfirmation) and affective responses (emotions) of customers which later will affect consumer behavior. Table settings will affect customer behavior (Ryu \& Han, 2011); and (6) service staff, which refers to employees within the premises of service. This refers to the employee's appearance, the number of employees, and the employee's gender. Tombs and McColl-Kennedy (2003) argued that service staffs are socially related in ways that affect the affective and cognitive responses of consumers and may influence customer's buying interest.

\section{Methodology}

This research is a quantitative research, using analysis factor with SPSS 19.0 for Windows. Supranto (2004) mentioned that factor analysis is a common name that denotes a class of procedures, primarily used to reduce data or summarize variables that have been changed to a few variables and call it a factor. According to Simamora (2005), the number of required factors sought is based on the concept. In this research, we used confirmatory factor analysis model, based on the concept from Ryu (2005) with six factors of physical environment of a restaurant. This research will be conducted at 22 new restaurants in Bali based on field survey data, food blogger social media, and TripAdvisor during the research period of April-July 2017. The restaurants as the sample in this research spread in 10 locations in Bali: Seminyak, Pecatu, Canggu, Jimbaran, Kerobokan, Denpasar, Kuta, Mengwi, Ubud, and Petitenget. The 10 locations are located in two regencies and one city of Badung, Gianyar, and Denpasar. This study was conducted in three areas only due to limited time, cost, and limitations of researchers.

This study used two types of data that are qualitative data and quantitative data. Qualitative data were obtained based on various information forms: interviews with owners or restaurant managers, and other data. Quantitative data are data in the form of numbers such as number of new restaurants in Bali, data on respondent characteristics during the study, as well as other data related to the research. The data sources used in this research are: primary data that are in the form of data obtained directly through research process such as sourced from result of customer questionnaire at 22 restaurants in Bali, result of interview with owner or manager of restaurant and secondary data that are sourced from TripAdvisor 2017 on new restaurants in Bali, journals on the restaurant's physical environment, as well as some related literature.

Respondents in this study were restaurant customers who had visited the 22 restaurants during the study period. Sample determination technique used in this research is non-probability sampling with accidental sampling method. Kusmayadi and Sugiarto (2000) explained the sampling using non-probability sampling to make a person's chances to become unknown respondents. Accidental sampling techniques are used without careful planning. The respondent asked for the information was actually obtained by chance without any particular consideration. Using this method, respondents who respond are determined by chance. For the purposes of data analysis using factor analysis, Supranto (2004) suggested that the sample size ( $n$ ) in factor analysis is at least four or five times the number of variables. Based on the consideration of time, cost, and data requirement according to factor analysis, the number of samples in this study is determined by 21 variables multiplied by five of 105 respondents. During the research period, questionnaires were distributed to customers in the 22 restaurants in Bali from April to July 2017. Research instruments use variables or indicators that are measured ordinal by using Likert scale. This scale is used to measure attitudes from the most positive level to the most negative level (Kusmayadi \& Sugiarto, 2000). In relation to the research of the 
effect of the physical environment on customer satisfaction in restaurants in Bali, respondents should express their views by choosing one of five alternative answers provided, namely: $5=$ very satisfied, $4=$ satisfied, 3 = quite satisfied, 2 = not satisfied, and 1 = very dissatisfied.

Before the research instrument is used to collect the data, then the instrument must be tested with the validity and reliability test. The purpose of the validity and reliability test is to test whether the questionnaire can measure what should be measured and have consistency of results when used by different researchers and respondents. According to Supranto (2004), the validity and reliability test is conducted on at least 30 respondents because with this number, the distribution of the score will be close to normal. According to Mantra and Kasto (1989), the validity test of measuring instrument is valid with the total score equaling to or more than 0.3 . While the reliability test of an instrument is said to be reliable when the value of Cronbach's alpha coefficient is greater than 0.6.

Based on DINESCAPE theory, there are six dimensions in this research with 21 attributes that exist related to a restaurant's physical environment. The six-dimensional distributions with the number of attributes are facility aesthetics (five variables), ambience (four variables), lighting (three variables), layout (four variables), table setting (three variables), and service staff (two variables). The role of the restaurant's physical environment is a construct that is immeasurable. The immeasurable factors will be measured ordinal through the Likert scale. Data collection techniques in this study used four ways: observation that is data collection by using participant observation techniques that directly enjoy the service at the restaurant sample research, as well as doing deep observations during the study period; interviews are data collections by way of question and answer directly by way of interview with parties related to the object of research such as the owner and/or restaurant managers during the study period; questionnaire is data collection by spreading the questionnaire to the respondents who are restaurant customers in Bali during the study period using two languages, namely, Indonesian and English. The questionnaires in this study used a closed questionnaire (fixed alternative question), questionnaires presented in the form of questions that the possible answer has been provided, so that respondents just need to choose one of the appropriate answers (Kusmayadi \& Sugiarto, 2000). The form of arrangement using the Likert scale to know the perception of tourists from very dissatisfied to very satisfied is associated with the object of research. According to Kusmayadi and Sugiarto (2000), the Likert scale is a tool for measuring positive attitudes and circumstances to a very negative level, to indicate the extent to which approval or disapproval of the statements submitted by the researcher is contained in the questionnaire. The literature is data collection conducted by reading the results of previous research related to the problems studied in several final reports, theses, magazines of tourism, papers and journals about the role of physical environment of restaurants and reference books, especially the concepts that support and are relevant to the problem under study.

Factor analysis is used for data analysis for the purpose of this study which is to determine the factors and variables that most play a role in knowing the perception of restaurant customers related to the role of physical environment in restaurants in Bali. According to Tenaya (2002), the first factor analysis stage is by formulating the problem, the second making a correlation matrix, the third determining the number of factors, the fourth rotating factor, the fifth determining the model accuracy, and the six interpreting factor. 


\section{Results and Discussion}

\section{Validity and Reliability Test}

Validity is an index indicating the extent to which a measuring instrument can be trusted or reliable. If the value of $R_{i}>0.3$, then the instrument can be declared valid and can be used in further research. Validity is tested using 30 respondents researched $(N=30)$. The results of validity test in this study show the interval of 0.313-0.614 which means that the research instrument has fulfilled the validity requirement with the total item-total correlation coefficient of each greater than $0.03\left(R_{i}>0.3\right)$. Thus, a feasible or valid research instrument is used as a data collector. Reliability is an index that indicates the extent to which a measuring instrument can be trusted or reliable to retrieve data. Tenaya (2002) argued that the instrument is reliable if the instrument is used multiple times to measure the same object and is able to produce relatively similar data. Therefore, reliability testing of the measuring instrument is intended to indicate the extent to which measuring instruments are reliable in data retrieval. The reliability test was performed by alpha-Cronbach variance test. If the alpha-Cronbach $R_{i}$ value $>0.6$, then the instrument is declared valid and can be used in the research. The result of instrument reliability test in this research is alpha coefficient of 0.765 . With a Cronbach alpha value of $0.765>0.6$, the instrument of this study can be trusted, reliable, and accurate as a data collector.

\section{Characteristics of the Respondents}

This study used the opinions of customers who had visited 22 restaurants during the study period of April-July 2017. The description of the characteristics of respondents is important because many aspects influence the customer satisfaction of the physical environment of restaurants in Bali. Characteristics of the respondents consist of: country of origin, sex, age, occupation, information about restaurant, and visit frequency. From the results of this research, the characteristics of customers who came to 22 restaurants in Bali in the study period are as follows: (1) country of origin: overseas customers (Asia, Europe, Australia, and America) (60\%), domestic customers (Jakarta, Surabaya, Yogyakarta, Balikpapan, and Papua) (40\%); (2) gender: female (60\%) and male (40\%); (3) age of tourists: from 15 years old to 50 years old; (4) employment: employee (35\%), entrepreneur (30\%), corporate leader (25\%), and student (10\%); (5) information about restaurants: friends (40\%), social media (40\%), and family (20\%); and (6) visit frequencies: two times (50\%), three times (40\%), and more than three times (10\%).

\section{Factor Analysis}

Often factor analysis is a preliminary analysis of a problem in research, namely in an attempt to get a new variable or latent variable that presents some items or dimensions that are observed variables. From latent variables or factors formed must be new data, which is a factor score value (FS), which is used as the basis of further analysis. The score value of the latent variable factor that is formed depends on the item or the dimension of the constituent. In this research, there is partial factor analysis in which each analysis uses factor confirmation analysis from the constituent items of each factor that is as much as six factors. Then, the six factors are coded as follows: (1) F1: facility aesthetics/facility aesthetics; (2) F2: atmosphere/ambience; (3) F3: lighting/lighting; (4) F4: layout/layout; (5) F5: table setting; and (6) F6: service staff/service staff.

The 21 variables form factors which are also coded as follows: X1: clean furniture; X2: interesting colors; X3: quality furniture; X4: attractive paintings/photos; X5: the wall decor is interesting; X6: comfortable room temperature; X7: a pleasant aroma; X8: background music; X9: voice background; X10: comfortable lighting; X11: effect of emotional lighting; X12: warm lighting; X13: comfortable seating arrangement; X14: special layout; X15: size and shape of layout; X16: planning a layout sufficient to move comfortably; X17: quality of 
cutlery; X18: options near the window; X19: linen is interesting; X20: tidy clothing and employee uniforms; and $\mathrm{X} 21$ : the number of employees is adequate. Looking at the observed variables, the factors can be formed in accordance with the grouping based on confirmatory factor analysis that is the factor which has been determined by its constituent components $\left(X_{i}\right)$. So the value of the factor score is determined by the component of the constituent component of the factor.

Facility aesthetics factor analysis (F1). The result of facility aesthetics factor analysis (F1) is the result of joint analysis (factor score $=$ FS) of five observed variables: X1: clean furniture; X2: interesting colors; X3: quality furniture; X4: attractive paintings/photos; and X5: the wall decor is interesting. After processing the data for the aesthetics factor of the facility (F1), as can be seen in the attachment, the obtained KMO value is 0.560 , which means that $\mathrm{KMO}>0.5$ and with the value of sig. $<0.000$ which means that all observed variables are feasible to be factored (Tenaya, 2002). However, when viewing the correlation anti-image X1-X5, there is one correlation anti-image value: $\mathrm{X} 4$. The attractive painting/photograph is 0.458 which is smaller than 0.5 , so the X4 variable must be removed from the facility aesthetics factor (F1) and must be re-invoked without the X4 variable. After elimination of variable X4 (attractive paintings/photos), then the results of the KMO test and its communality can be seen that the result of factor analysis of the five variables that play a role in the aesthetics factor of the facility (F1) is valid with a KMO value of 0.574 which is greater than 0.05 and a significance value (sig.) of 0.000 which is smaller than 0.05 ; so it can be said that $\mathrm{X} 4$ (attractive paintings/photos) does not play a role in the establishment of the facility aesthetics factor (F1).

The role of each variable on the factors formed can be known from the value of communality. The result of KMO test and communality of facility aesthetics factor (F1) states percentage of each factor variable in forming facility aesthetics factor (F1) which can be explained by factors formed, such as variable X1 (clean furniture) equaling to $69.2 \%$, variable $\mathrm{X} 2$ (interesting colors) equaling to $61.2 \%$, variable $\mathrm{X} 3$ (quality furniture) equaling to $35.2 \%$, and variable X5 (interesting wall decoration) equaling to $35.2 \%$. It turns out that X1 (clean furniture) has the highest role in the formation of facility aesthetics factor (F1), followed by X2 variable (interesting colors) and the smallest one is X3 (quality furniture) and X5 (interesting wall decoration). The eigenvalue and matrix components of the facility aesthetics factor (F1) state that the aesthetics factor of facility (F1) can represent its forming component of $60.680 \%$ of the total variance, which means that one factor represents the four variables $\mathrm{X} 1, \mathrm{X} 2, \mathrm{X} 3$, and X5 with the initial eigenvalue of 1.400 which is greater than 1.00 . Then, the results of matrix component analysis show the closeness of correlation or correlation of each variable from X1 to X5 which make up the aesthetics factor of facility (F1). The higher the value of the matrix component of each variable, the stronger the relationship of the variable or the greater the role in the formation of factors. It can be seen that the $\mathrm{X} 1$ (clean furniture) has the strongest relationship to the aesthetics factor of facility (F1) with the correlation coefficient of 0.832 , followed by the variable X2 (interesting colors) with a correlation coefficient of 0.782; and the weakest is X3 (quality furniture) and X5 (attractive wall decorations) with a correlation coefficient of 0.594 .

Atmosphere factor analysis (F2). Result of atmosphere factor analysis (F2) is the result of joint analysis (factor score) from four variables, that is, X6 (comfortable room temperature), X7 (a pleasant aroma), $\mathrm{X} 8$ (background music), and X9 (sound background). After data processing, we got a KMO value equaling to 0.546 , meaning that $\mathrm{KMO}>0.5$ and with the value of sig. $<0.000$ which means that all observed variables are feasible to be factored. So with a KMO value of 0.546 as shown, it shows that the correlation between pairs of factor-forming variables can be explained by other variables and an appropriate factor analysis is performed. And if we see the anti-image correlation $\mathrm{X6-X9}$ as in the attachment, the value is all already greater than 0.5 . 
The role of each variable in the factors formed can be known from the value of communality. The result of KMO test and atmosphere factor communiqués (F2) states the percentage of each factor variable in forming atmosphere factor (F2) that can be explained by the factors formed, such as X6 variable (comfortable room temperature) equaling to $74.7 \%$, variable X7 (pleasant aroma) equaling to 59.5\%, variable X8 (background music) of $36.0 \%$, and variable $\mathrm{X} 9$ (sound background) of $7.8 \%$. It turns out that variable X6 (comfortable room temperature) has the highest role in the formation of atmosphere factor (F2), followed by X7 variable (pleasant aroma), and the lowest variable is X9 (sound background). The eigenvalues and matrix components of the atmosphere factor (F2) state that the atmosphere factor (F2) can represent the forming component of $60.500 \%$ of the total variance, which means that one factor represents the four variables of X6-X9 with the initial eigenvalue of 1.780 which is greater than 1.00 . The results of matrix component analysis show the correlation relationship or correlation of each variable from X6 to X9 which make up the atmosphere factor (F2). The higher the value of the matrix component of each variable, the stronger the relationship of the variable or the greater the role in the formation of factors, and vice versa. It can be seen that the X6 variable (comfortable room temperature) has the strongest relationship to the atmosphere factor (F2) with the correlation coefficient of 0.864 , followed by the variable X7 (pleasant aroma) with a correlation coefficient of 0.771 ; and the weakest is the $\mathrm{X} 9$ variable (sound background) with a correlation coefficient of 0.280 .

Lighting factor/lighting (F3). The result of lighting factor analysis (F3) is the result of joint analysis (factor score = FS) from three observed variables, that is, X10 (comfortable lighting), X11 (effects of emotional lighting), and X12 (warm lighting). After data processing, we got the KMO value of 0.475 which is smaller than 0.5 ( $\mathrm{KMO}<0.5)$ with the value of sig. $<0.423$ which means that all observed variables are not feasible to be factored. So with the KMO value of 0.475 as shown in the attachment, it is shown that the correlation between pairs of variable-forming factors cannot be explained by other variables and factor analysis has not been done. So to make the lighting factor (F3) valid to be factored, we will look for and exclude one lighting factor-forming variable that has the lowest correlation anti-image value. X12 (warm lighting) has the smallest anti-image value, so this variable must be removed from the lighting factor (F3), then it must be re-done without the X12 variable. After elimination of X12, the result of KMO test and the factor of enrichment community (F3) shows that the result of factor analysis of two variables that play a role in the lighting factor (F3) is valid to be factored with a KMO value of 0.500 (requirement that KMO value should be equal to or $>0.5$ ) and significance value (sig.) of 0.000 ; so it can be said that the variable X12 does not play a role in the formation of the lighting factor (F3).

The role of each variable in the factors formed can be known from the value of communality. The result of KMO test and the lighting factor (F3) states the percentage of each factor variable in the formation of the lighting factor (F3) which can be explained by the factors formed, such as X10 (comfortable lighting) which is $54.2 \%$ and $\mathrm{X} 11$ (precision of emotional effect of enrichment) which is also equal to $54.2 \%$. From these results, the two variables are X10 and X11 which play the same role in the formation of lighting factor (F3). The eigenvalue and the exposure factor matrix (F3) state that the lighting factor (F3) represents the composition component of $64.160 \%$ of the total variance, which means that one factor represents the two variables X10 and X11, with an initial eigenvalue value of 1.083 , which is greater than 1.00 . The results of matrix component analysis show the closeness of the correlation or correlation of each variable of X10 and X11 that make up the lighting factor (F3). The higher the value of the matrix component of each variable, the stronger the relationship of the variable or the greater the role in the formation of factors. It can be seen that X10 (comfortable lighting) has a strong relationship with X11 (emotional lighting) on the lighting factor (F3) with the correlation coefficient of 0.736. 
Layout factor analysis/layout (F4). The result of layout factor analysis (F4) is the result of joint analysis (factor score = FS) from four observed variables, that is, X13 (comfortable seating arrangement), X14 (special layout), X15 (the size and shape of the layout), and X16 (planning a layout sufficient to move comfortably). After processing the data for the layout factor (F4), we obtained KMO value of 0.638 meaning that KMO $>0.5$ and with the value of sig. $<0.000$ which means that all observed variables deserve to be factored (Tenaya, 2002). So, it is with a KMO value of 0.638 . It shows that the correlation between pairs of factor-forming variables can be explained by other variables and an appropriate factor analysis is performed. And if we see the anti-image correlation value X13 to X16 as in the attachment, its value is all greater than 0.5.

The role of each variable in the factors formed can be known from the value of communality. The result of KMO and communality of layout factor (F4) states the percentage of each factor variable in forming layout factor (F4) which can be explained by the factors formed, such as X13 (comfortable seating arrangement) which is $64.4 \%$, X14 (special layout) of 57.3\%, X15 (size and shape of the layout), and X16 (layout planning enough to move comfortably) the same that is equal to $52.00 \%$. It turns out that X13 (comfortable seating arrangement) has the highest role in the formation of layout factor (F4), followed by X14 (special layout) and the smallest of the four variables are X15 (size and shape of the layout) and X16 (layout planning enough to move comfortably). The eigenvalues and layout matrix factor (F4) state that the layout factor (F4) represents the forming component of $60.920 \%$ of the total variance, which means that one factor represents the four variables X13-X16 with the root value (initial eigenvalue) of 1.737 which is greater than 1.00 . Then, the results of matrix component analysis show the closeness of the correlation or correlation of each variable from X13 to X16 which construct the layout factor (F4). The higher the value of the matrix component of each variable, the stronger the relationship of the variable or the greater the role in the formation of factors, and vice versa. The X13 (comfortable seating arrangement) has the strongest relationship to layout factor (F4) with a correlation coefficient of 0.802 , followed by variable X14 (special layout) with a correlation coefficient of 0.757, and X15 (size and shape of the layout) and X16 (layout planning enough to move comfortably) with a correlation coefficient of 0.721 .

Analysis of guest setting factor/table setting (F5). The result of the analysis of table setting factor (F5) is the result of joint analysis (factor score $=$ FS) of three observed variables: X17 (quality of cutlery), X18 (options near the window), and X19 (the linens were interesting). After processing the data for table setting factor (F5), as can be seen in the attachment, the obtained KMO value is 0.658 which means that KMO $>0.5$ and with sig. $<0.000$ which means that all observed variables are feasible to be factored (Tenaya, 2002). So, it is with a KMO value of 0.658 . It shows that the correlation between pairs of factor-forming variables can be explained by other variables and an appropriate factor analysis is performed. And if it is seen that the anti-image correlation $\mathrm{X} 17$ to $\mathrm{X} 19$ is in the attachment, its value is all greater than 0.5 .

The role of each variable in the factors formed can be known from the value of communality. The result of KMO test and table setting factor communality (F5) states the percentage of each variable factor in the formation of table setting (F5) which can be explained by the factors formed, such as X17 (quality of cutlery) of 68.4\%, X18 (choice near the window) of $64.0 \%$, and X19 (interesting linen) equaling to $62.00 \%$. It turns out that X17 (the quality of cutlery) has the highest role in the formation of table setting factor (F5), followed by X18 variable (choice near the window) and the smallest of the three variables is X19 (interesting linen). The eigenvalue and matrix components of table setting factor (F5) state that table setting factor (F5) can represent the forming component of $60.820 \%$ of the total variance, which means that formed one factor represents three variables of X17-X19 with the initial eigenvalue of 1.730 which is greater than 1.00 . Then, the results of matrix component 
analysis show the closeness of correlation or correlation of each variable from X17 to X19 which make up the table setting factor (F5). The higher the value of the matrix component of each variable, the stronger the relationship of the variable or the greater the role in the formation of factors. It can be seen that the X17 variable (quality of cutlery) has the strongest correlation to table setting factor (F5) with a correlation coefficient of 0.815 , followed by X18 variable (choice near the window) with a correlation coefficient of 0.756; and the weakest relationship is X19 variable (interesting linen) with a correlation coefficient of 0.721 .

Service staff factor analysis/service staff (F6). The result of service staff factor analysis (F6) is the result of joint analysis (factor score $=$ FS) of two observed variables: X20 (tidy clothing and uniforms of employee) and X21 (sufficient number of employees). After processing data for service staff factor (F6), we got the KMO value of 0.602 which means that $\mathrm{KMO}>0.5$ and with the value of sig. $<0.000$ which means that all observed variables are feasible to be factored (Tenaya, 2002). So with a KMO value of 0.602 , it shows that the correlation between pairs of factor-forming variables can be explained by other variables and an appropriate factor analysis is performed. And if we see the anti-image correlation value X20 and X21 as in the attachment, its value is all greater than 0.5 .

The role of each variable in the factors formed can be known from the value of communality. The results of the KMO test and the factor communication of the service staff (F6) state the percentage of the roles of each factor constituent variable in the shaping factor of service staff (F6) that can be explained by the factors formed, such as X20 (tidy clothing and uniforms of employee) of 58.5\% and X21 (adequate number of employees) of $64.5 \%$. It turns out that X21 (adequate number of employees) has the highest role in the formation of service staff factors (F6), followed by X20 (tidy clothing and uniforms of employee). The eigenvalue of service staff factor (F6) states that the service staff factor (F6) can represent the forming component of $60.820 \%$ of the total variance, which means that one factor represents the two variables X20 and X21 with the initial eigenvalue of 1.745 which is greater than 1.00. Then, the matrix component analysis results show the closeness of the correlation or correlation of each variable of X20 and X21 that make up the service staff factor (F6). The higher the value of the matrix component of each variable, the stronger the relationship of the variable or the greater the role in the formation of factors. It can be seen that the X21 variable (adequate number of employees) has the strongest relationship to service staff factor (F6) with a correlation coefficient of 0.645 , followed by X20 variable (tidy clothing and uniforms of employee) with a correlation coefficient of 0.585 .

\section{Analysis of Customer Satisfaction}

From the above factor analysis, it can be seen that each factor has the most powerful or decisive variable for the factor that is: (1) facility aesthetics factor (F1) with variable X1 (clean furniture) with a correlation coefficient of 0.832; (2) atmosphere factor (F2) with variable X6 (comfortable room temperature) with a correlation coefficient of 0.864; (3) lighting factor (F3) with variable X10 (convenient lighting) and variable X11 (emotional effect of lighting) with a correlation coefficient of 0.736; (4) layout factor (F4) with X13 variable (comfortable seating arrangement) with a correlation coefficient of 0.802; (5) guest table setting factor (F5) with variable X17 (quality of guest dining equipment) with a correlation coefficient of 0.815 ; and (6) service staff factor (F6) with variable X21 (adequate number of employees) with the correlation coefficient of 0.645. Based on the purpose of this study and the results of the above analysis, we can conclude that variable X6 (comfortable room temperature) has the strongest role in forming atmosphere factor (F2) with the correlation coefficient of 0.864 , followed by X1 (clean furniture) of facility aesthetics (F1) with a correlation coefficient of 0.832 . 
The interpretation is as follows: (1) the facility aesthetics factor analysis (F1) shows that the restaurant customers when they have nice dining experience at a restaurant in Bali are concerned with clean furniture compared to attractive colors, quality furniture, and attractive wall decorations. The results of interviews with the owners or managers in the restaurant show that if the furniture is dirty, guests will not feel comfortable then they will very easily complain or go especially in the hours that are very busy. So the cleanliness of the furniture as part of the aesthetic facilities should receive a considerable portion of attention so as to maintain the quality of the restaurant; (2) the atmosphere factor analysis (F2) shows that restaurant customers as they enjoy themselves at a restaurant in Bali are concerned with a comfortable restaurant room temperature rather than a pleasant aroma, background music, or sound background. The results of interviews with the owners or managers of the restaurant show that they try to maintain the room temperature so that their customers are comfortable while enjoying their eating experience. If the restaurant has outdoor (outdoor) or smoking area facilities, they will ensure a comfortable air circulation for their customers; (3) the lighting factor analysis (F3) shows that restaurant customers as they enjoy their dining experience at a restaurant in Bali are concerned with comfortable lighting including the emotional effects that result from existing lighting. Interviews with the owners and managers of the restaurant show that the lighting is very supportive then the atmosphere effects will be generated, especially during dinner time; (4) the layout factor analysis (F4) shows that restaurant customers as they enjoy their dining experiences at a restaurant in Bali are particularly concerned with comfortable seating arrangements rather than special layouts, layout sizes and shapes, and layout planning sufficient to move comfortably. The results of interviews with the owners and managers of the restaurant are that now there are many reasons for their customers to come to the restaurant because they want to be with the family, colleagues, and friends. Comfortable seating arrangements enable restaurant customers to have both privacy and comfortable mobility of motion. Therefore, restaurant managers will focus more on the seating arrangements of customers so as to make it more comfortable for them; (5) the analysis of guest table arrangement (F5) shows that restaurant customers as they enjoy their dining experience at a restaurant in Bali are particularly concerned with the quality of guest dining equipment rather than near-window choices or the availability of attractive linens. The results of interviews with the owners and managers of the restaurant show that with quality dining equipment, the guests will be more satisfied, especially if the equipment is in accordance with the function and design to follow the development of the era or trend of contemporary society; and (6) the service staff analysis (F6) shows that restaurant customers as they enjoy their dining experience at a restaurant in Bali are concerned with an adequate number of employees rather than the tidiness of clothing and employee uniforms. Interviews with the restaurant owners and managers suggest that the adequacy of employees who will provide services to customers at restaurants is more important in maintaining customer satisfaction of the restaurants. Customer satisfaction to the physical environment of 22 new restaurants in Bali gave very satisfied input (55\%), followed by satisfied (35\%) and neutral (10\%) of the overall general rating by 117 restaurant customers. This indicates that the customers are very concerned with the atmosphere of a safe and comfortable restaurant when they enjoy their eating experience. In general, customers also suggest that the restaurant should provide free Wi-Fi or Internet connection for its customers as an effort in providing satisfaction for its customers. 


\section{Conclusion}

Based on the discussion in the previous chapter, we obtained the following results: (1) The most determinant factor of customer satisfaction in restaurants in Bali to its physical environment is atmosphere factor (F2) followed by facility aesthetics factor (F1); (2) variable that most determines the satisfaction of customers in restaurants in Bali to the physical environment is variable X6 (comfortable room temperature) followed by variable X1 which is clean furniture; and (3) in general, customers at new restaurants in Bali expressed satisfaction with the physical environment of the restaurant where they enjoyed their eating experience.

The results of this study can be useful for restaurant management in Bali, for the government, and for other researchers. For the restaurant management in Bali, it should be able to improve the factors that have not been good and maintain the already good factors, especially the physical environment of the restaurant. For the government, it should pay more attention to the quality of products and infrastructure facilities in restaurants in Bali so as to be able to maintain customer satisfaction. For other researchers, the results of this study can be used as a reference related to customer satisfaction at restaurants in Bali.

\section{References}

Banat, A., \& Wandebori, H. S. T. (2012). Store design and store atmosphere effect on customer sales per visit economics. Paper presented at The 2nd International Conference on Business, Economics, Management and Behavioral Sciences, Bali, Indonesia.

Elina, N. D. (2016). Analisa pengaruh physical environment terhadap minat beli konsumen di kafe-kafe di Surabaya. Jurnal Hospitality dan Manajemen Jasa, 4(2), 411-423.

Hussain, R., \& Ali, M. (2015). Effect of store atmosphere on customer purchase intention. International Journal of Marketing Studies, 7(2), 35-43.

Kim, W. G., \& Moon, Y. J. (2009). Customers' cognitive, emotional, and actionable response to the servicescape: A test of the moderating effect of the restaurant type. International Journal of Hospitality Management, 28(1), 144-156.

Kusmayadi \& Sugiarto, E. (2000). Metode Penelitian dalam Bidang Kepariwisataan. Jakarta: PT Gramedia Pustaka Utama.

Lin, I. Y. (2004). Evaluating a servicescape: The effect of cognition and emotion. International Journal of Hospitality Management, 23(2), 163-178.

Mantra, I. B., \& Kasto. (1989). Penentuan Sampel dalam Metode Penelitian Survai. Editor Masri Singarimbun dan Sofian Effendi. Jakarta: LP3ES.

Ryu, K. (2005). DINESCAPE, emotions and behavioral intentions in upscale restaurants (Doctoral dissertation, Kansas State University).

Ryu, K., \& Han, H. (2011). New or repeat customers: How does physical environment influence their restaurant experience? International Journal Hospitality Management, 30(3), 599-611.

Ryu, K., \& Jang, S. (2007). The effect of environmental perceptions on behavioral intentions through emotions: The case of upscale restaurants. Journal of Hospitality \& Tourism Research, 31(1), 56-72.

Ryu, K., \& Jang, S. (2008). DINESCAPE: A scale for customers' perception of dining environments. Journal of Foodservice Business Research, 11(1), 2-22.

Simamora, B. (2005). Analisis Multivariat Pemasaran. Jakarta: PT Gramedia Pustaka Utama.

Supranto, J. (2004). Pengukuran Tingkat Kepuasan Pelanggan Untuk Menaikkan Pangsa Pasar. Jakarta: Rineka Cipta.

Tenaya, I. M. N. (2002). Kuantivikasi data Kualitatif dengan metode MSI (Metode Suksesif Interval-MSI). Laboratorium Statistika. Fakultas Pertanian. Universitas Udayana.

Tombs, A., \& McColl-Kennedy, J. R. (2003). Social-servicescape conceptual model. Marketing Theory, 3(4), 447-475.

Tuzunkan, D., \& Albayrak, A. (2016). The importance of restaurant physical environment for Turkish customers. Journal of Tourism Research and Hospitality, 5(1), 1-7.

Wall, E. A., \& Berry, L. L. (2007). The combined effects of the physical environment and employee behavior on customer perception of restaurant service quality. Cornell Hospitality Quarterly, 48(1), 59-69. 